\title{
Enabling Geographic Research Across Disciplines: Building an Institutional Infrastructure for Geographic Analysis at Harvard University
}

\section{Citation}

Guan, Weihe Wendy, Bonnie Burns, Julia L. Finkelstein, and Jeffrey C. Blossom. 2011. “Enabling Geographic Research Across Disciplines: Building an Institutional Infrastructure for Geographic Analysis at Harvard University." Journal of Map \& Geography Libraries 7 (1) (January 6): 36-60. doi:10.1080/15420353.2011.534688.

\section{Published Version}

doi:10.1080/15420353.2011.534688

\section{Permanent link}

http://nrs.harvard.edu/urn-3:HUL.InstRepos:26848435

\section{Terms of Use}

This article was downloaded from Harvard University's DASH repository, and is made available under the terms and conditions applicable to Other Posted Material, as set forth at http:// nrs.harvard.edu/urn-3:HUL.InstRepos:dash.current.terms-of-use\#LAA

\section{Share Your Story}

The Harvard community has made this article openly available.

Please share how this access benefits you. Submit a story. 
1 Enabling Geographic Research across Disciplines: Building an institutional

2 infrastructure for geographic analysis at Harvard University

3 Weihe Wendy Guan ${ }^{1}$, Bonnie Burns ${ }^{2}$, Julia L. Finkelstein ${ }^{3}$ and Jeffrey C. Blossom ${ }^{4}$

4 Abstract

5 Founded in 1818, the Harvard Map Collection (HMC) is the oldest map collection in

6 America, holding 400,000 maps, more than 6,000 atlases and thousands of reference books.

7 HMC has a strong commitment to digital resources and manages the Harvard Geospatial Library,

8 a foundation for geospatial data service at Harvard. The Center for Geographic Analysis at

9 Harvard University (CGA) was founded in 2006, independent of the library system, to serve the

10 entire university. This article presents the history, organizational structure, and operational

11 model of CGA and HMC, reviews achievements, lessons learned, suggests future improvements,

12 and reviews GIS-related medical research at Harvard.

\section{Historical Background}

14 Harvard lost its Geography Department in 1948 (Smith, 1987) and the Computer

15 Graphics and Spatial Analysis Lab in 1991(Chrisman, 2006). The support for maps and

\footnotetext{
${ }^{1}$ Corresponding author, Harvard University Center for Geographic Analysis. 1737 Cambridge St., Suite 350, Cambridge, MA 02138 USA. wguan@cga.harvard.edu.

${ }^{2}$ Harvard Map Collection

${ }^{3}$ Harvard School of Public Health

${ }^{4}$ Harvard University Center for Geographic Analysis
} 
16 geographic analysis for medicine research and much of the rest of the University fell on the

17 Harvard Map Collection (HMC) $)^{5}$ alone, with limited resources. By the early 2000s the

18 University recognized that it was missing out on the potential contributions the new geography -

19 the approach to geospatial analysis that combined Geographic Information Systems (GIS)

20 technology with quantitative analysis - could make to disciplines across the university, from

21 medicine to epidemiology to sociology to history to trade policy. The question the University

22 faced was how most effectively, and quickly, to make it possible for students and faculty to bring

23 geospatial to bear on research and teaching (Guan and Bol, 2010). The Center for Geographic

24 Analysis (CGA) ${ }^{6}$ was established to do just that (Gehrman, 2006), with a mandate to collaborate

25 closely with the Map Collection and the ongoing digital library project named the Harvard

26 Geospatial Library $^{7}$ (HGL; Siegel, et al. 2004).

\section{The History of the Harvard Map Collection}

28 The HMC, a unit under the Harvard College Library, was founded in 1818 with the gift

29 of the Ebeling Collection of 10,000 maps and books, presented to the University by Israel

30 Thorndike (Figure 1). The Collection has grown consistently since that time. With the transfer

31 of maps after the dissolution of Harvard's Institute for Geographic Exploration, the HMC became

32 one of the largest map collections in North America. Visiting the HMC is an opportunity to see

33 some of the cartographic treasures of the world, since the stacks contain not just paper but also

34 digital materials (Figure 2).

\footnotetext{
${ }^{5}$ Harvard Map Collection website: http://hcl.harvard.edu/libraries/maps/

${ }^{6}$ Center for Geographic Analysis website: http://cga.harvard.edu/

${ }^{7}$ Harvard Geospatial Library website: http://hgl.harvard.edu
} 
35 Figure 1 New York State by D.F. Sotzmann, 1799. From the Ebeling Collection, Harvard

\section{Map Collection}

37 Figure 2 Harvard Map Collection reading room, photograph by Peter Vanderwarker, 38 courtesy of Harvard College Library

The HMC began its GIS activities in earnest in 1992. More and more cartographic

40 materials were being made available in digital form, but at that time the HMC had only a single

41 PC and it was dedicated to browsing the library catalog. There were data but no methods for

42 library patrons to access them, since the library had no GIS workstations and the staff had

43 minimal GIS experience. There was no support outside of the library on GIS either. The

44 Harvard Graduate School of Design ${ }^{8}$ had a strong GIS presence, but support was limited to

45 students in that school. For undergraduates and graduate students in other programs, there were

46 very few options.

47 At that time, the Association of Research Libraries (ARL) ${ }^{9}$ launched the GIS Literacy

48 Project, an effort "to introduce, educate, and equip librarians with skills needed to provide access

49 to spatially referenced data in all formats and to provide effective access to selected electronic

50 information resources in library collections"(Adler 1995). ARL solicited donations and support

51 from the GIS industry to achieve its goals of increased GIS presence in academic libraries. The

52 HMC was in the first wave of libraries to be awarded such support and began to build up the

\footnotetext{
${ }^{8}$ Harvard GSD website: http://gsd.harvard.edu

${ }^{9}$ ARL website: http://www.arl.org/
} 
53 infrastructure and staff needed to provide the research community with a place to go for GIS

54 data, software and help.

55 The first step was to provide access to the materials on the HMC shelves. Computers in

56 the reading room were installed with a variety of GIS and cartographic software programs for

57 general use. Staff were trained in ArcView and started to answer requests from patrons for

58 simple custom map requests. Students and researchers soon saw value of GIS and requests for

59 assistance became more and more complex, to the point where in 1999, a GIS specialist was

60 hired in the HMC to assist with GIS data creation, analysis and programming.

61 In addition to creating an infrastructure for GIS support in the library, the HMC began, in

62 1995, to bring GIS to the Internet via the Massachusetts Electronic Atlas (MEA). Hosted by the

$63 \mathrm{HMC}$ and created by Harvard, UMass Boston and the Metropolitan Area Planning Council, the

64 MEA allowed users to map over 200 variables for the state, including extensive health data, as

65 well as crime statistics and natural resources information (Cobb, 1995). The site proved to be

66 quite popular and useful, but did not allow for data downloading and also only covered

67 Massachusetts, and therefore did not include data of interest to most students.

68 A new project was envisioned in 1998, a system that would allow patrons to have access

69 to the rich collection of data in the Harvard libraries at all hours via the Internet (Siegel, et al

70 2004). This system would not only serve data for download but include a robust search engine

71 allowing users to quickly find relevant data without having to browse a file system. By 2001, the

72 Harvard Geospatial Library (HGL) was live and receiving 300 hits per day.

73 HGL currently holds over 6,000 data layers that are ready for use in geographic

74 information systems (Figure 3). These layers are at a variety of scales - from global (VMAP 1)

75 to local (cadastral data for Boston) - cover many different areas of the world, and range in age 
76 from current to 400 year-old historic maps. The catalog is based on detailed Federal Geographic

77 Data Committee ${ }^{10}$ Content Standard compliant metadata records that allow for finely tuned

78 searches of the repository. Users can display and download these layers for use in their desktop

79 software.

$80 \quad$ Figure 3 The Harvard Geospatial Library Entry Page

81 In addition to current library holdings, HGL is also a distribution mechanism for

82 researcher-created datasets. When GIS projects lead to the creation of new data, those files can

83 be sent to the HMC for inclusion in the repository and catalog. This ability to accept GIS data

84 for distribution led to further collaborations with the CGA since 2006.

\section{The Establishment of the Center for Geographic Analysis}

86 The field of geographic analysis underwent a series of revolutions in the past half a

87 century. The quantitative revolution brought quantitative analysis into geography in the 1950s,

88 which inspired a new generation of students and scholars (Dutton, 2006). The birth of geographic

89 information systems in the 1960s equipped geographic analysis with computers (Niemann and

90 Niemann, 1998). Computer cartography and analysis of remotely sensed images in the 1970s

91 presented new dimensions to the discipline. The integration of geographic analysis with

92 numerical models gained much ground in the 1980s, especially in the field of environmental

93 studies. The information technology (IT) boom in the 1990s gave geographic analysis a swift

94 push into the IT mainstream, complete with relational and object-oriented database management

95 systems (RDBMS and ODBMS), programming platforms, client server architectures, and web-

${ }^{10}$ FGDC website: http://www.fgdc.gov 
96 based implementations. The completion of the Global Positioning System (GPS) and the ever

97 increasing earth surveillance satellites resulted in an exponential increase of spatial data in native

98 digital format, feeding content to, and at the same time putting pressure on, the geographic

99 information systems. By the middle of 2000s, Google released Google Maps and Google Earth,

100 which generated a heightened public interest in geographical issues and expanded awareness of

101 geography in other disciplines. The geo-technological revolution is still ongoing as of today,

102 pushing geographic analysis up to computing clouds and down to mobile devices, into the hands

103 of all walks of life. Its continued growth has expanded job market for geographers, increased

104 enrollment in geography departments, and brought improvement in geography education at all

105 levels (Murphy, 2007).

106 In 2003, a faculty committee on spatial analysis was formed at Harvard University, led by

107 Professor Peter Bol, a prominent historian and a pioneer in applying GIS to the study of history.

108 The committee was set to find a solution to address the increasing concerns from faculty and

109 students on improving access to spatial data, support for research employing geospatial analysis,

110 and curriculum development. Two years of investigation and discussion led to the decision by

111 the University President and Provost to establish the Center for Geographic Analysis (CGA). The

112 inauguration of the Center was held in May 5, 2006 (Gehrman, 2006), some called the day "a

113 new dawn for geography at Harvard" (Waters, 2006).

114 From day one, the CGA has been focused on research and education in the field of spatial

115 analysis and geographic information. Building on the foundation established by the HMC and

116 HGL, the CGA was expected to create a more substantial infrastructure to support a wide range

117 of scholarly research projects that wish to apply, improve, or study geospatial analysis 
118 techniques. One of the largest and most advanced user groups is Harvard's medical and public

119 health research community.

\section{Multifaceted Medical Research at Harvard University}

Medical research is conducted at a number of institutions at Harvard University, including the Harvard School of Public Health, Harvard Medical School (Figure 4), and affiliated hospitals, the Harvard Humanitarian Initiative, the Harvard Initiative for Global Health, and the Faculty of Arts and Sciences. The following section will describe the application of geographic analysis and GIS to medical research being conducted at Harvard University.

\section{Figure 4 The Harvard Medical Campus}

\section{Application of Geographic Analysis to Medical and Public Health Research}

The early applications of geographic analysis to medical research can be traced to a small Soho district in London in 1854. John Snow, a British physician, identified the Broad Street water pump as the source for one of the most severe cholera epidemics in history, by using observational data and a series of maps. Based on this work, he is considered the father of modern epidemiology, one of the cornerstones of public health (Singer and de Castro 2001). John Snow's study was a transformative event in the history of medical geography and public health. The handle of the Broad Street pump has become a symbol, marking the integration of medicine, geographic analysis, and public health research.

Over 150 years since John Snow's cholera outbreak investigation, geographic analysis remains intricately linked to medical research. The application of spatial analytic techniques to understand the distribution of disease and determinants of health is at the core of medical and public health research. During the past two decades, advances in technologies have made it 
140 possible to examine spatial and temporal trends in large-scale epidemiological data with 141 enhanced precision and speed.

142 GIS techniques are ideally suited for public health surveillance and infectious disease 143 control, as transmission of infectious diseases is closely related to geographic proximity. This 144 includes case location, identification of clustering, mapping of epidemic dynamics, and mapping 145 disease burden and response. More recently, geographic analytic methods have been applied to 146 the fields of environmental health and chronic disease epidemiology, to link proximity to 147 exposures to incidence of non-communicable diseases. Application of GIS methods and 148 collaborative data sharing has also contributed to the emerging fields of crisis mapping, response 149 to natural disasters, and infectious disease outbreaks, to inform timely targeted emergency 150 responses, resource allocation, and health care delivery strategies.

151 Understanding spatial and temporal distribution of disease is central to targeting health

152 problems. Using GIS facilitates exploration of a broad range of determinants - such as

153 demographic, socioeconomic, geographic, and environmental factors - from a diverse array of

154 disciplines that influence disease transmission patterns in a single environment.

155 Geographic analysis provides a unique interface between health data and a map - to 156 effectively present information to key decision-makers. GIS methods enable summation and 157 presentation of large amounts of data for disease surveillance and health reporting, and identify 158 new cases, map at-risk populations, stratify risk factors, and quantify distribution of risk and 159 transmission patterns. Optimal summary and visual presentation of complex medical and 160 scientific health data can be used to communicate abstract quantitative data, and inform health 161 care policy, program planning, and health resource allocation. Geographic analysis also informs 162 evidence-based policy and program planning, such as the design, implementation, and 
163 monitoring of targeted interventions, and examining patterns of disease burden and health care

164 delivery. Selected examples of applying geographic analysis to medical research at Harvard

165 University are presented in Table 1.

166 Table 1 Selected Medical Research Projects at Harvard University

167 Examples of Geographic Information Systems in Medical Research at Harvard

168 Geographic analysis and examining medical research questions spatially have helped to

169 integrate medical and public health research across disciplines and departments at Harvard

170 University. For example, the Exposure, Epidemiology and Risk Program (EER) at the Harvard

171 School of Public Health brings together the departments of Environmental Health and

172 Epidemiology to explore environmental and occupational determinants of health and disease, and

173 inform evidence-based policy.

174 Researchers have applied novel GIS techniques and cutting-edge statistical methods to

175 longitudinal epidemiological studies, to answer unanticipated research questions not envisioned

176 at the study onset. The Nurses Health Study, founded in 1976 in the Department of Nutrition, is

177 among the largest and longest running investigations of factors that influence women's health.

178 Started in 1976, this study of over 238,000 nurses has led to many new insights on health and

179 disease. Researchers in the Exposure, Epidemiology and Risk Program, Department of

180 Environmental Health, and the Departments of Nutrition and Epidemiology have applied GIS

181 techniques to analyze data from the Nurses' Health Study, and use semi-empirical models to

182 predict spatially and temporally resolved long-term average outdoor concentrations of particulate

183 matter (PM) (Yanosky, Paciorek et al. 2008) and successfully predict chronic fine and coarse

184 particulate exposures using spatio-temporal models for the Northeastern and Midwestern United 
185 States (Yanosky, Paciorek et al. 2009). Spatial methods are also being incorporated into new 186 research designs for longitudinal studies; in fact, the third Nurses Health Study is currently 187 underway over three decades later, to examine environmental and lifestyle exposures of women.

188 Similarly, researchers have applied GIS methods to examine long-term ambient multi189 pollutant exposures (PM10, PM2.5, nitrogen dioxide, and sulfur dioxide) in 53,814 men in the 190 US trucking industry, and found that residential ambient air pollution exposures were associated 191 with significantly increased mortality (Hart, Garshick et al. 2010). GIS methods have also been 192 applied to the Harvard Six Cities Study, one of the most influential, innovative and longest193 running studies addressing the health effects of air pollution in America; this landmark study has 194 led to the regulation of airborne particulate matter and the development of the Clean Air Act.

195 Geographic analysis has also been used in medical research to target advocacy and social 196 justice in resource-limited settings. In an example of geographic analysis bringing together the 197 university with the community, researchers examined the influence of traffic on air quality in an 198 urban neighborhood (Buonocore, Lee et al. 2009). In this project in the Mission Hill 199 neighborhood of Boston, Massachusetts, GIS methods were used to examine spatial and 200 temporal patterns of traffic-related air pollutants to determine factors contributing to elevated 201 concentrations and inform environmental justice concerns. In another project in Malawi, Africa, 202 investigators used GIS methods and data from the Malawi Health Facility Inventory and the 203 Malawi Demographic and Health Survey to identify disparities in access to modern reproductive 204 health services (Heard, Larsen et al. 2004).

205 Geographic analysis has been transformative in international medical research at Harvard 206 University. GIS technologies have allowed researchers to send portable GPS units to remote field 207 settings to monitor conflict zones, urban slums, and remote villages, and provide precise health 
208 data in areas with limited infrastructure. GIS and remote sensing technologies have also been

209 used to identify host habitats and identify clusters of cases, to examine infectious disease

210 transmission patterns, and inform targeted interventions. For example, researchers in the

211 Department of Nutrition at the Harvard School of Public Health used GIS methods to examine

212 ecological determinants of parasitic infections in school children in rural KwaZulu-Natal, South

213 Africa, including Ascaris lumbricoides (Saathoff, Olsen et al. 2005) and hookworm (Saathoff,

214 Olsen et al. 2005). Researchers in the department of Global Health and Population also obtained

215 complete coverage of larval control to suppress malaria vector mosquitoes through

216 comprehensive spatial coverage with community-derived sketch maps in Dar es Salaam,

217 Tanzania (Dongus, Nyika et al. 2007). Researchers also used spatial and temporal analysis of

218 malaria risk to inform policies for disease control in the Amazon region in Brazil (Singer and de

219 Castro 2001).

220 Geographic analysis has also emerged with increasingly important humanitarian projects.

221 In the aftermath of natural disasters, such as the 2010 earthquake in Haiti, GIS technologies have

222 played a critical role in rapid and efficient response to crises, and in conducting public health

223 research to develop and monitor evidence-based programs. GIS also plays an important role in

224 crisis mapping initiatives and developing early warning systems to mitigate the effects of natural

225 disasters, avert mass atrocities, strengthen international aid coordination, inform resource

226 allocation, and develop evidence-based humanitarian interventions.

227 The Harvard Humanitarian Initiative (HHI) is a university-wide center involving multiple 228 entities within the Harvard community that provide expertise in public health, medicine, social

229 science, management, and other disciplines to respond to humanitarian complex emergencies. In

230 the Humanitarian Crisis Mapping and Early Warning project, GIS methods and mapping 
231 technologies are used to promote evidence-based approaches to humanitarian assistance, and

232 advancing the science and practice of humanitarian response worldwide. For example, in the

233 Incubator Implementation project in Indonesia, GPS devices were used to map remote areas

234 where incubators were placed. Within the HHI and the Harvard medical community at large,

235 researchers understand the utility of GIS technology in their research and use it for a diverse

236 range of projects.

237 Collaborations Between CGA and HMC

238 In order to effectively support the diverse needs for geographic analysis from the Harvard

239 medical community as well as the rest of the university at large, CGA established a governing

240 structure which includes faculty members from the medical school and the school of public

241 health in its faculty steering committee, and key GIS professionals from the library and the

242 medical campus in its technical advisory committee. The faculty committee meets once per

243 semester to guide the center in its strategic development, while the technical advisory committee

244 meets three times per semester to advise the center in its technical operation, such as service

245 level and distribution, technology adaptation, outreach event coordination, and feedback from the

246 user community. Staff of HMC and HGL serves on the CGA technical committee, while CGA

247 staff serves on the HGL Standing Committee. This cross-organizational structure provides a

248 forum for regular checks and balance of the shared responsibilities between the CGA and the

249 HMC in optimizing user support.

250 Data Acquisition, Development, and Sharing

251 Data is usually the first thing a user asks for when considering geographic analysis.

252 Utilizing each organization's strength, the HMC focuses on systematically acquiring geospatial 
253 data, making them available, and helping users find the appropriate data precisely and quickly

254 from the Harvard library holdings. The CGA often refers users to the HMC for data-related

255 questions, such as data availability, source, cost, and format. Patrons interested in historical data

256 are often forced to create that data on their own by digitizing paper maps, and HMC has a larger

257 format scanner that can be used to create an image of any material in the collection. Those

258 images can be georeferenced with assistance from either CGA or HMC and the relevant

259 information can be digitized. When the user receives their data, they may return to CGA for help

260 in analyzing and visualizing the data. If the patron requires less complex analysis or

261 straightforward cartography, they can get that help at HMC.

262 Many research projects require unique data that are not acquired by the library yet and

263 are not available from well known public data sources, such as international data, high resolution

264 images, or custom-created data by a researcher or a research institution. CGA facilitates the

265 identification of such data sources, helps define and clarify the data properties and quality, serves

266 as the liaison between Harvard data users and some data companies and institutions, manages

267 data development service and cross-institutional data sharing contracts, and assists the users in

268 submitting their unique data to the HGL with proper permission. The HMC takes on the

269 responsibility of geospatial data stewardship alone, freeing the CGA to focus on analysis

270 services.

271 Whether data is acquired by CGA or HMC, the goal is to hold onto it and make it

272 available to future researchers. While licensing restrictions sometimes prohibit data sharing,

273 whenever possible, new data are deposited into the HGL. For that the data are delivered to HMC

274 and translated into the HGL accepted format (ArcSDE layers). Metadata that is compliant with

275 the FGDC standard is created by the Harvard College Library geospatial resources cataloger, and 
276 the data is published via HGL. Many layers are restricted to Harvard affiliates only, but all

277 metadata is publically searchable so that non-Harvard researchers can at least discover that a data

278 set exists and get information on how to obtain the layer for themselves. Every effort is made to

279 license data for use by the entire Harvard Community. However sometimes that is just not

280 possible, and only a single user is allowed access at any time. In those cases, metadata is still

281 created and placed in the HGL catalog, with information on where to access the data set on

282 campus. By collaborating in this way, CGA and HMC have increased the size and value of the

283 HGL collections as well as the usefulness of the system to patrons.

\section{Software Licenses and Labs}

285 The CGA manages all University-wide geospatial software license contracts, and equips

286 computer labs across the University with updated versions of GIS, image processing, spatial data

287 conversion, visualization and geostatistical analysis software packages from multiple companies,

288 as well as some freeware and open source GIS tools. Most of these software licenses are

289 managed through a centralized license server, with one or two backup servers to maintain

290 uninterrupted availability. The HMC maintains a small lab of PCs equipped with GIS software

291 distributed by CGA, as well as powerful desktop publishing applications that can be used to

292 create professional quality illustrations.

293 The Harvard medical community has unique license requirements because of its

294 geographically distributed nature. Many Harvard Medical School and HSPH faculty members

295 also work in the various hospitals in Boston. The CGA provides special assistance to them,

296 making sure that their research and teaching needs are supported by the university floating 
297 licenses, while these licenses are not mistakenly used in the hospitals' operation, which would be

298 a violation of the university site license agreement.

\section{Training Programs}

Before the establishment of the CGA, the HMC GIS staff offered hands-on training in

301 both GIS and remote sensing, which were converted into online tutorials. These tutorial materials

302 continued to be available online through the HMC website. In addition, the CGA offers a multi-

303 faceted GIS training program both on the main campus and on the Longwood medical campus.

304 This includes a number of credit courses at the introduction level, the senior thesis level, and the

305 graduate student level, tailored to meet different needs from students in different disciplines,

306 such as social sciences, environmental sciences, engineering, and public health. It also includes

307 non-credit courses, and a series of hands-on training seminars of geographic analysis tools and

308 methodologies open to all Harvard affiliates every Friday during the academic year. Since 2009,

309 the CGA has added a 10-day intensive training program called the Harvard GIS Institute, for

310 faculty and graduate students who wish to learn GIS during the winter or summer breaks. The

311 program is so popular that some applicants have to wait for a year to obtain a seat in it. Software

312 specific self-learning tutorials are easily accessible from the CGA website as well.

313 These training programs and the CGA's technical consultation services feed and backup

314 each other, and combined with the HMC's data service form a balanced support network to users

315 with different needs. Some researchers come to CGA for technical consultation first, but as their

316 projects develop, they realize that it would be more efficient if they themselves can do some

317 hands-on GIS work, thus they sign up for the training, and gradually become more independent

318 in designing and conducting their geographic analysis. On the contrary, some researchers have 
319 unrealistic goals in their geographic analysis project at first. After taking the training courses, 320 they realize that GIS is not as simple as just learning to use a piece of software. Their time is

321 better spent on focusing on their disciplinary topics, leaving the geographic analysis work to the

322 CGA staff. Thus they became more frequent users of the CGA analytical services after the 323 training.

324 Many students who took these courses or training programs went on to apply geographic 325 analysis in their thesis or dissertation work. In the past five years, one of the authors who served 326 on the review committee for the Howard T Fisher Prize in GIS ${ }^{11}$ witnessed significant

327 improvement in the complexity and quality of GIS work among the award applicants. This 328 observation is shared by all members of the review committee.

\section{Consultation and Help Desks}

330 The CGA has designated office hours when users can walk in and ask for help (Figure 5).

331 Questions addressed at the CGA help desks include where to find certain data, how to do certain 332 analysis, which software tool is most appropriate for certain projects, how much to budget for 333 geographic analysis in certain grant proposals, which GPS model meets certain field work needs, 334 how to design the database or web service for certain projects, how to quickly learn certain GIS 335 skills, and many more. The CGA help desks on the main campus and the medical campus, 336 together with the virtual help desk (24 hour response time by email and/or phone) served over 337100 inquires per month on average. Users range from faculty members, research associates, post-

\footnotetext{
${ }^{11}$ The Howard T Fisher Prize in GIS website: http://gis.harvard.edu/icb/icb.do?keyword=k235\&pageid=icb.page190018
} 
338 doctoral fellows, graduate and undergraduate students, and staff, to visiting scholars. Among

339 them, graduate students are the most numerous help desk users.

$340 \quad$ Figure 5 The CGA Front Office and Help Desk

The HMC reference desk gets GIS and digital data requests daily, and the questions tend

342 to be from patrons who may not even know what GIS is or how it can help them. There are no

343 set hours for GIS-related questions, since patrons are just as likely to be looking for a road atlas

344 as for GIS help. Patrons with time consuming requests are often asked to schedule an

345 appointment, and complex projects are referred back to CGA. Most GIS interactions are with

346 undergraduates, but there are also many graduate students who are introduced to GIS for the first

347 time at the HMC reference desk.

$348 \quad$ Analytical Services

349 In some cases, a help desk visit could lead to a follow up consultation session, which

350 could lead to a more dedicated service project. At this capacity, the CGA operates like an

351 internal consulting firm, working with the users to define project scope, specify deliverables,

352 estimate risks and uncertainties, plan alternatives, set schedules and milestones, and calculate

353 service costs. Most of such service projects are completed internally by CGA staff, but a portion

354 of them involves outsources services too. For those cases, the CGA staff would identify

355 appropriate external service providers, negotiate service contracts, communicate technical

356 requirements, perform quality assessment and quality control on their deliverables, and manage

357 the external contracts for the end users. Work requiring external services are usually labor

358 intensive (such as digitizing features from historical maps), or highly specialized (such as

359 developing a software module to plug into certain CGA systems). Another type of CGA service 
360 supports teaching directly, where the CGA staff would develop and deliver a customized GIS

361 training module for a non-GIS class or research team. Such training is usually followed up by

362 more hand-holding when the students or researchers start to use what they have learned to apply

363 geographic analysis in their course work or research project. The authors will discuss more

364 specific geographic analysis service cases in support of medical research at Harvard in the next

365 issue of this publication.

\section{Technology Monitoring}

367 With the rapid evolution of the geospatial technology, many faculty and students find that 368 even after investing significant amount of time learning the GIS tools, it is still very hard to keep

369 their skills and knowledge up to date with the changes. They could be proficient with one version

370 of a popular software, or one model of a popular equipment, but a couple of years later, they are

371 at a loss again when facing the new versions, new models, new data formats, and new

372 visualization trends. The CGA staff serves as the geospatial technology steward for the Harvard

373 GIS user community, monitoring, evaluating, reporting, selectively acquiring new technology

374 products, and introducing new methodologies, standards, architectural platforms, and technology

375 services. They attend the major geospatial conferences periodically, subscribe to the popular

376 technical newsletters and journals, and remain active in the geospatial professionals' circle. In

377 return, they publish a monthly newsletter to over 1000 readers, and maintain the CGA website

378 which averages over 1000 hits daily.

379 The CGA also hosts annual conferences, providing a forum for the Harvard users to

380 exchange ideas and experiences with invited scholars on geospatial technology and its

381 application in designated fields. Conference themes range from GIS, remote sensing, 
382 geocoding/georeferencing, spatial-temporal modeling, technology applications in the study of

383 religion, global temporal gazetteer development, and web mapping. Another technology forum is

384 co-sponsored by the CGA and the Harvard grass-root technology group called ABCD-GIS ${ }^{12}$. The

385 monthly brownbag seminars bring out speakers from the Harvard GIS professionals community

386 and other universities, companies or government agencies. It is open to the GIS community at

387 Harvard and beyond.

\section{Web Map Services}

389 Anyone who has kept an eye on the geospatial technology trend in recent years would not

390 have missed the wave of web services. In addition to the HGL discussed earlier, the CGA has

391 developed and continues to enhance a number of web mapping applications, engaging in a

392 variety of technology platforms from ArcGIS Server (ESRI, 2008), to GoogleMap API, to

393 complete open source systems built on OpenLayers, MapServer and PostgreSQL (Lewis and

394 Guan, 2010). Among them are several applications in support of medical research, such as the

395 Surgical Safety Web Map and the Emergency Department Web Map. These applications will be

396 discussed in detail in the next issue of this publication.

397 The WorldMap is an example of collaboration between the CGA and the HMC at the

398 system development and collections levels. It was built to assist academic research and teaching

399 as well as the general public with an open source system that allows for discovery, investigation,

400 analysis, visualization, communication and archival of multi-disciplinary, multi-source and

401 multi-format data, organized spatially and temporally. The first instance of WorldMap was

\footnotetext{
${ }^{12}$ The ABCD-GIS group website: http://www.abcd.harvard.edu/harvard/groups/abcd-gis/
} 
402 focused on the continent of Africa, called AfricaMap (Lewis and Guan, 2010) ${ }^{13}$. Since its beta

403 release in November of 2008, the framework has been implemented in several different locations

404 with different research focuses, including metro Boston, East Asia, Vermont geological sites,

405 Harvard Forest and the city of Paris. These web mapping applications are used in courses as well

406 as by individual researchers. Figure 6 shows the Malaria seasonal variation overlaid on

407 population density in AfricaMap.

408 Figure 6 Malaria Seasonal Variation Overlaid on Population Density in AfricaMap

409 Some data layers presented in the WorldMap systems are contributed by the HMC, and

410 some data layers acquired by these systems are in turn submitted to the HMC for long term

411 archiving. Moreover, critical data layers in these systems are included in HGL, and the

412 download function calls an HGL download service directly. This cross-system integration avoids

413 the duplication of data storage and system development, offering the users a seamless experience

414 utilizing both systems behind the scenes. Further integration is under development which will

415 allow for cross-serving of data layers between the two systems as web map services (WMS) and 416 web feature services (WFS).

\section{Conclusion}

418 The HMC, with a history of nearly two centuries, and the CGA, with merely 5 years of

419 existence, form the core components of the infrastructure in support of geographic analysis at

420 Harvard University today. Their success relies on collaboration, not only between each other, but

421 also with various research support organizations in the schools and departments throughout the

\footnotetext{
${ }^{13}$ AfricaMap website: http://africamap.harvard.edu
} 
422 University (Figure 7). The CGA's Technical Advisory Committee includes members from not

423 only the libraries, but also the Harvard-MIT Data Center, the Institute for Quantitative Social

424 Sciences, the Instructional Computing Group of the Faculty of Arts and Sciences, the Computer

425 Resources Group of the Graduate School of Design, the Harvard School of Public Health, the

426 Harvard Planning \& Allston Initiative, FAS Department of Earth and Planetary Science, and the

427 School of Engineering and Applies Sciences. Each of these organizations provides infrastructure

428 support to their department, school, or the University at large, and covers different technology

429 domains, such as statistical analysis, database management, web design and development,

430 computer aided design, three-dimensional visualization, and system engineering. Geospatial

431 technology intertwines with these technology domains, and the CGA receives support from these

432 organizations while providing support to them at the same time. The CGA staff could be an end

433 user of their service in one project, a collaborative partner in another project, and a subject matter

434 expert offering consultation service to them in yet another project. For example, the CGA is an

435 end user of the Dataverse Network (DVN) for data archiving and dissemination; the CGA staff

436 and the DVN development team are working together to explore methodologies for mapping the

437 study cased in the DVN; and the CGA built a geographic location finder tool for the DVN users

438 to populate the latitude and longitude fields in the metadata when they submit data to the DVN.

439 Figure 7 The institutional relationship among CGA, HMC and other organizations

440 These multi-dimensional collaborations form a support web, providing many places and

441 methods for patrons to start their projects with the proper technology support, and to be guided to

442 geographic analysis if their projects call for it. This support web also ensures that the people in

443 each place work together, each according to their own strengths, to get the patron the help he 
444 needs. It avoids redundant capacity building, which is critically important in the current financial 445 hardship. For example, the CGA does not invest in long term data repository. All geospatial data 446 that are worth archiving are handed over to the HMC to be properly cataloged, loaded into HGL

447 for user download, and archived in the Harvard Digital Repository Service (DRS).

448 Such a collaborative infrastructure is not without challenges. Harvard University has the

449 tradition of being a distributed system, with each organization operating under autonomous

450 terms, described as "every tub has its own bottom." Many excellent support teams are focused on

451 supporting their own department or school only, with no mandate or capacity to provide support

452 across the administrative boundaries. The CGA's operational model broke this tradition. It was

453 established to serve the entire University from the beginning. But five years into its operation,

454 the CGA has yet to reach out to all potential users. The demand on CGA's service is still

455 growing exponentially, almost doubling every year (Figure 8). Outreach and coordination

456 continues to be major tasks for CGA, competing for limited resources with technical projects.

457 Figure 8 CGA help desk number of tickets (2006-2010)

458 Moreover, for users who are familiar and satisfied with CGA services, CGA became their

459 "one-stop shop" for technology support. It is often hard for the end user to clearly define their

460 project's need for the different technical domains. Often times, one project needs data

461 acquisition, database design, web development, geographic analysis, and statistical modeling.

462 The researcher may not be familiar with all the specialty support teams for each of these

463 components. They may rely on CGA, or whichever team that they are most familiar with, to help

464 them define their project scope, identify technology needs, and establish initial contact with the

465 other specialty teams. 
The CGA's operational model not only bridged among the technical support teams, but

467 also made cross-disciplinary and cross-school connections. People from all parts of the

468 university come to CGA for assistance in finding data, making maps, selecting analytical tools or

469 receiving training. The broad user contacts put CGA staff in a unique position to help make cross

470 disciplinary connections for scholars. An epidemiologist from the Harvard School of Public

471 Health might be looking for the same census data as a political scientist from the Harvard

472 Kennedy School of Government studying violence; and an entomologist from the Harvard

473 Museum of Comparative Zoology may be interested in building the same digital elevation model

474 and hydrologic network as a historian or archaeologist studying ancient trade routes. Through the

475 CGA, some of them became aware of other's work in the same region of the world, made

476 contacts to each other, shared base data and local data sources, coordinated equipment usage

477 (such as GPS), and some even found other's work inspiring to their own research (Guan and Bol, 478 2009).

The CGA started with a humble beginning of 3 FTEs and a 2-room office. By the fifth

480 year, it has doubled its annual budget, tripled its staff, and quadrupled its office space. The core

481 funding from the Provost Office allowed for the CGA to offer basic services free of charge to

482 anyone with a Harvard ID, including help desk, non-credit training, and initial consultation

483 service. An educational endowment supports the GIS Institute, and income from service projects,

484 grants and gifts make up the rest of the operational budget. By focusing on serving everybody

485 else across the University, the CGA gradually advanced its own status, despite the financial

486 hardship in the past year.

The HMC and the CGA share the same mission of enabling geographic research across

488 disciplines. The quest to building an institutional infrastructure for geographic analysis at 
489 Harvard University has just begun. As the geospatial technology evolves, and people's

490 awareness and expectation increase, both the HMC and the CGA will continue to adapt and

491 adjust in order to improve efficiency and effectiveness, to better serve research and teaching at

492 Harvard University.

493 Acknowledgements

494 The authors wish to thank HMC and CGA colleagues for their input and support to the 495 work represented in this manuscript, especially those from Professor Peter Bol, the Charles H. 496 Carswell Professor of East Asian Languages and Civilizations and the Director of the CGA.

\section{References}

498 Adler, Prudence S. 1995. A Special Issue of Geographic Information Systems and Academic 499 Libraries: And Introduction. Journal of Academic Librarianship 21(4):233-235

500 Buonocore, J. J., H. J. Lee, et al. (2009). "The influence of traffic on air quality in an urban neighborhood: a community-university partnership." Am J Public Health 99 Suppl 3:

503 Chrisman, Nick. 2006. Charting the Unknown: How Computer Mapping at Harvard Became GIS. ESRI Press

505 Cobb, David A. 1995. Developing GIS Relationships. Journal of Academic Librarianship 21(4):275-277

507 Cobb David A. and Arlene Olivero. 1997. Online GIS Service, Journal of Academic 
Dongus, S., D. Nyika, et al. (2007). "Participatory mapping of target areas to enable operational larval source management to suppress malaria vector mosquitoes in Dar es Salaam, Tanzania." Int J Health Geogr 6: 37.

512 Dutton, Geoffrey. 2006. Everything is where it is having moved there. A memoir on the occasion of the dedication of the Harvard Center for Geographic Analysis.

ESRI. 2008. China Earthquake Geospatial Research Portal Launched by Harvard University. ArcNews Online, Fall 2008. http://www.esri.com/news/arcnews/fall08articles/chinaearthquake.html

Gehrman, Elizabeth. 2006. Geography center launched - Center for Geographical Analysis to explore 'vast intellectual territory'. Harvard Gazette. May 11, 2006. http://www.news.harvard.edu/gazette/2006/05.11/05-geography.html.

Guan, Weihe (Wendy) and Peter Bol, 2010. Embracing Geographic Analysis beyond Geography - Harvard's Center for Geographic Analysis enters its $5^{\text {th }}$ year. International Journal of Applied Geospatial Research (in press)

Guan, Weihe (Wendy) and Peter Bol. 2009. Harvard Revisited: Geography's Return as GIS. In The Geography Teacher 6(2), published by Taylor \& Francis.

Guan, Weihe (Wendy) and Guoping Huang. 2009. Bringing Operational GIS into University

528 Gudrais, Elizabeth. 2010. Harvard Center's Maps Help Haiti Effort. Harvard Magazine, January

529 19, 2010. http://harvardmagazine.com/breaking-news/harvard-center-hosts-haiti-map-

$530 \quad$ portal 
531 Hart, J. E., E. Garshick, et al. (2010). "Long-term Ambient Multi-pollutant Exposures and Mortality." Am J Respir Crit Care Med.

533 Heard, N. J., U. Larsen, et al. (2004). "Investigating access to reproductive health services using 534 GIS: proximity to services and the use of modern contraceptives in Malawi." Afr J Reprod Health 8(2): 164-179.

Kaplan, Robert M. 2006. Medical Geography-Who Gets the Goods? More May Not Be Better. In Optimizing Health: Improving the Value of Healthcare Delivery. Edited by Franz Porzsolt and Robert M. Kaplan. Published by Springer US.

Lewis, Benjamin and Weihe (Wendy) Guan. Jump Starting the Next Level of Online Geospatial Collaboration: Lessons from AfricaMap. In Advances in Web-based GIS, Mapping Services and Applications. Songnian Li, Suzana Dragicevic and Bert Veenendaal, eds. (in press)

Murphy, Alexander B. 2007. Geography's Place in Higher Education in the United States. Journal of Geography in Higher Education 31(1): 121 - 141

Niemann, Bernard J. Jr. and Sondra (Sue) Niemann. 1998. GIS Innovator - Allan H. Schmidt: GIS Journeyman. GeoInfoSystems, May and October, 1998

Reed, Christopher. 2006. Hello, Geotech - "Modeling our world,” geography returns to Harvard.

Saathoff, E., A. Olsen, et al. (2005). "Ecological covariates of Ascaris lumbricoides infection in schoolchildren from rural KwaZulu-Natal, South Africa." Trop Med Int Health 10(5): 412-422. 
553 Saathoff, E., A. Olsen, et al. (2005). "Ecologic covariates of hookworm infection and reinfection in rural Kwazulu-natal/south Africa: a geographic information system-based study." Am J Trop Med Hyg 72(4): 384-391.

556 Siegel, David, Bonnie Burns and Tim Strawn. 2004. HGL: A Web-Enabled Geospatial Digital Library. ESRI International Conference Proceedings, 2004. http://proceedings.esri.com/library/userconf/proc04/docs/pap1024.pdf

Singer, B. H. and M. C. de Castro (2001). "Agricultural colonization and malaria on the Amazon frontier." Ann N Y Acad Sci 954: 184-222.

Smith, Neil. 1987. Academic War Over the Field of Geography: The Elimination of Geogrpahy at Harvard, 1947-1951. Annals of the Association of American Geographers, 77(2):155-

Sui, Daniel Z. Sui. 2007. Geographic Information Systems and Medical Geography: Toward a New Synergy. Geography Compass 1(3): 556 - 582

Waters, Nigel. 2006. Harvard, Geography and GIS: A Race to the Top, M2MEDIA360.

Yanosky, J. D., C. J. Paciorek, et al. (2008). "Spatio-temporal modeling of chronic PM10 exposure for the Nurses' Health Study." Atmos Environ 42(18): 4047-4062.

570 Yanosky, J. D., C. J. Paciorek, et al. (2009). "Predicting chronic fine and coarse particulate exposures using spatiotemporal models for the Northeastern and Midwestern United States." Environ Health Perspect 117(4): 522-529.

573 Youngblood, Dawn. 2009. A Case Study in Proactive Development: David Cobb, Harvard 


\section{List of Figures}

575 Figure 1 New York State by D.F. Sotzmann, 1799. From the Ebeling Collection, Harvard Map

576 Collection

577 Figure 2 Harvard Map Collection reading room, photograph by Peter Vanderwarker, courtesy of

578 Harvard College Library

579 Figure 3 The Harvard Geospatial Library entry page

580 Figure 4 The Harvard Medical Campus

581 Figure 5 The CGA front office and help desk

582 Figure 6 Malaria seasonal variation overlaid on population density in AfricaMap

583 Figure 7 The institutional relationship among CGA, HMC and other organizations

584 Figure 8 CGA help desk number of tickets (2006 - 2010)

$585 \quad$ List of Tables

586 Table 1 Selected Medical Research Projects at Harvard University 